\title{
Developmental stability and environmental stress in Salmo salar (Atlantic salmon)
}

\author{
LEIF ASBJØRN VøLLLSTAD* $+\&$ KJETIL HINDAR $\ddagger$ \\ †Department of Biology, Division of Zoology, University of Oslo, P.O. Box 1050 Blindern, N-0316 Oslo and \\ $\ddagger$ Norwegian Institute for Nature Research, Tungasletta 2, N-7005 Trondheim, Norway
}

\begin{abstract}
We have studied the developmental stability (measured as fluctuating asymmetry of five meristic characters) of three populations of Atlantic salmon Salmo salar (rivers Imsa, Lone and Ogna, western Norway). All three populations were both sampled in the wild, and hatched and reared in a common environment in a hatchery (with water from the river Imsa) from fertilization until smoltification. Both the Imsa and Lone hatchery populations have been sea-ranched in the Imsa for 10 years, whereas the Ogna populations is novel to the hatchery environment. Individual biochemical heterozygosity was scored at $50 \mathrm{loci}$, of which 11 were polymorphic. There was no correlation between biochemical heterozygosity and fluctuating asymmetry at the individual level, neither when tested within groups nor when tested between groups. There were no differences in fluctuating asymmetry between wild and hatchery Imsa and Lone fish, indicating that the hatchery environment did not disrupt early developmental homeostatic processes. However, the Ogna hatchery fish had significantly elevated levels of fluctuating asymmetry compared to the wild Ogna fish, indicating that the hatchery environment was hostile. The Ogna hatchery fish also had significantly higher fluctuating asymmetry than the Imsa hatchery and the Lone hatchery fish. Maladaptation to the hatchery environment is the most likely explanation for the increased asymmetry in river Ogna fish.
\end{abstract}

Keywords: developmental stability, fluctuating asymmetry, hatchery environment, heterozygosity, Salmo salar, water quality.

\section{Introduction}

The morphology of an individual is produced by the developmental process that transforms the genotype into the phenotype. The ability of development to produce a targeted phenotype despite potential disturbing factors is termed developmental stability (Leary et al., 1992) or noise resistance (Van Valen, 1962). Fluctuating asymmetry (hereafter FA), defined as small random departures from perfect symmetry, is commonly used as a measure of the developmental stability of bilaterally symmetrical morphological traits (Clarke, 1992; Palmer \& Strobeck, 1992). The underlying theory of FA suggests that the presence of environmental or genetic stress during ontogeny reduces the efficiency of normal developmental processes, thus increasing the level of FA (Clarke, 1992). Developmental stability seems to

${ }^{*}$ Correspondence. E-mail: asbjorn.vollestad@bio.uio.no be reduced by increased homozygosity, by hybridization between nominal species, by extreme physical conditions, and by pollution or habitat deterioration (Leary \& Allendorf, 1989; Clarke, 1992, 1995; Palmer \& Strobeck, 1992; Markow, 1995).

In fishes several studies indicate a negative correlation between FA and level of heterozygosity as estimated from enzyme electrophoretic studies (see Leary et al., 1992). However, there is also a number of examples in fish where no such correlations are found (Beacham, 1991; Ferguson \& Ihssen, 1991; Karakousis \& Triantaphyllidis, 1992). Thus, there is clearly a need for more studies on the relationship between developmental stability and heterozygosity. The other main factor affecting developmental stability is environmental stress of some kind. A large number of papers present evidence that environmental stress increases FA (see Leary \& Allendorf, 1989). In most fish studies, the relationship between heterozygosity and FA, and between 
environmental stress and FA, is based on hatcheryreared populations (e.g. 17 of 20 populations in Leary et al. (1992) are hatchery-reared). Thus, the interpretation of these relationships is made difficult by possible confounding factors, such as the use of artificial spawning and environmental stress imposed on natural populations brought into captivity.

In this study we test whether the developmental stability of meristic characters of Atlantic salmon Salmo salar changes when three natural populations are brought into a common hatchery environment. We do this by measuring FA on wild juvenile Atlantic salmon from three different water courses (rivers Imsa, Lone and Ogna) in western Norway. Further, eggs from Atlantic salmon originating in these three rivers were hatched in a hatchery receiving water from the Imsa, and the progeny raised there to the smolting stage. The Imsa and Lone populations have been sea-ranched in the Imsa for 10 years prior to sampling of hatchery fish (there has been no mixing of populations), whereas the Ogna hatchery strain was formed by parental fish caught in the Ogna. Thus, the Imsa hatchery population has had a longterm adaptation to the water quality and a shortterm adaptation to the hatchery environment at Ims, the Lone hatchery population has had a short-term adaptation to both, and the Ogna hatchery population is novel to the water quality as well as to the hatchery environment.

Based on this we test two general hypotheses. (1) FA is negatively correlated with heterozygosity within and between groups of Atlantic salmon juveniles (three localities, wild and hatchery origin). (2) FA is positively correlated with environmental stress within and between groups.

The first hypothesis was tested both by measuring FA of five meristic characters and by biochemical heterozygosity, based on enzyme electrophoretic data, on all sampled juveniles. The second hypothesis was tested by examining how FA varied between populations in their native environment and in a common hatchery environment. In particular, we expected that lack of adaptation to hatchery life should be reflected in increased FA in the Ogna hatchery population, whereas lack of adaptation to Imsa water quality should be seen as increased FA in both non-native populations (Ogna and Lone). At the individual level environmental stress is more difficult to define. Here, we assumed that it is inversely proportional to the individual growth rate, which is strongly environment-dependent in fishes (Stearns, 1992), and we tested the hypothesis that FA is negatively correlated with growth rate within each group of Atlantic salmon juveniles.

\section{Materials and methods}

The rivers Lone $\left(60^{\circ} 31^{\prime} \mathrm{N}, 5^{\circ} 31^{\prime} \mathrm{E}\right)$, Ogna $\left(58^{\circ} 19^{\prime} \mathrm{N}\right.$, $\left.6^{\circ} 02^{\prime} \mathrm{E}\right)$ and Imsa $\left(58^{\circ} 54^{\prime} \mathrm{N}, 5^{\circ} 58^{\prime} \mathrm{E}\right)$ are small rivers (mean discharge 4-5 $\mathrm{m}^{3} \mathrm{~s}^{-1}$ ) located in southwestern Norway. All are coastal rivers with agricultural lands and a number of small lakes in the catchment, and an oceanic climate with mild winters and cool summers. The water chemistry is more or less the same in the three rivers (at the locations where young salmon were sampled). All three rivers produce small, early maturing salmon (exclusively or predominantly one sea-winter fish).

Wild Atlantic salmon juveniles were obtained either by electrofishing (Ogna and Lone), or by capture in a Wolff trap (Imsa; for description of the trap see Vøllestad et al. (1994)). The wild Ogna juveniles were captured in the small tributary Gåslandsbekken on 13 May 1992, the wild Lone juveniles were captured on 24 October 1991. The wild Imsa juveniles (mostly smolts) were captured in the Wolff trap during May 1990 and May 1991. All fish were frozen at $-80^{\circ} \mathrm{C}$ as soon as possible after a capture. The wild Ogna, Imsa and Lone salmon were in the length intervals $58-98 \mathrm{~mm}, 113-260$ $\mathrm{mm}$, and $80-132 \mathrm{~mm}$, respectively.

Hatchery strains of the three populations were raised at the Research Station for Freshwater Fish at Ims, south-western Norway. In autumn 1989, gametes were pooled from 7-50 Atlantic salmon of each sex and locality to produce three hatchery strains, the Imsa, Lone and Ogna hatchery strains. The Imsa and Lone hatchery strains were produced from sea-ranched parents which migrated in the Imsa watercourse. A two-way fish trap on this river prevents the mixing of wild and sea-ranched fish. The Ogna hatchery strain was formed from wild parents caught in the Ogna. The eggs were incubated and later reared in $4 \mathrm{~m}^{2}$ outdoor tanks for one year at ambient temperatures of the Imsa. The fish were fed to satiation on dry pellet food. Mortality was registered daily. Differences between the three hatchery strains in survival rate were tested using the Lee-Desu test statistic from the SPSs/PC + statistical package. Juveniles of all hatchery strains were sampled on 18 March 1991 at lengths of 61-242 $\mathrm{mm}$.

The fish were measured $(\mathrm{mm})$ and scales and otoliths were collected for age determination (Jonsson, 1976). As a measure of individual growth rate, we used back-calculated length at the end of the first growing season (Imsa wild juveniles), length upon sampling (all hatchery-reared juveniles which were sampled at the same age, Ogna wild juveniles 
which turned out to be of the same age), or the length by age interaction in a full factorial ANCOVA model (Lone wild juveniles).

We counted the number of pectoral and pelvic fin rays, the number of gill rakers at the upper and lower part of the first gill arch (Leary et al., 1983), and the number of mandibular pores on both the right $(\mathrm{R})$ and the left $(\mathrm{L})$ side of the fish. In some cases counts of gill rakers could not be performed because of disruption at the gill arch. Asymmetry was estimated as the signed difference between the right and left side ( $\mathrm{R}-\mathrm{L})$. Fluctuating asymmetry is defined statistically in terms of the $R-L$ distributions being normally distributed around a mean of zero (Van Valen, 1962). This may be an idealistic situation, and recent studies indicate that leptokurtotic R-L distributions also may indicate FA (Jagoe \& Haines, 1985; Clarke et al., 1992; Palmer and Strobeck, 1992). We used the number of asymmetric characters for each individual as our index of developmental stability. There was no correlation between absolute asymmetry and size, therefore it was not necessary to standardize asymmetry values by correcting for size differences. We tested for the presence of antisymmetry and directional symmetry (Van Valen, 1962) by visual inspection of the R-L distribution, by testing for mean $=0$, and by testing for skewness and kurtosis.

Tissue samples of skeletal muscle, liver and eye were stored at $-80^{\circ} \mathrm{C}$ until required for biochemical analysis. Horizontal starch gel electrophoresis was performed as described by Aebersold et al. (1987). The buffer systems used, the proteins examined, and the genetic interpretations of the electrophoretic banding patterns followed Ståhl (1987), with additional systems being described by Jordan et al. (1992) and Wilson et al. (1995). The designation of loci, alleles and genotypes is according to Shaklee et al. (1990). Variant alleles are designated according to their electrophoretic mobility relative to the common $(* 100)$ allele.

Genetic variation was found at the following 11 loci, with the observed variant alleles added to the locus designation: aspartate aminotransferase $A A T-4 * 25, \quad * 50, \quad$ fructose-biphosphate aldolase FBALD-3*95, N-acetyl- $\beta$-glucosaminidase $\beta G L U A$ *130, glucose-6-phosphate isomerase GPI-1,2*185, L-iditol (sorbitol) dehydrogenase IDDH- $1 * 20$, $I D D H-2 * 80$, L-lactate dehydrogenase $L D H-4 * 60$, malate dehydrogenase $M D H-3,4 * 75, * 80$, malic enzyme $M E P-2^{*} 125$, and triosephosphate isomerase TPI-1*-150, TPI-3*95,*105. Variation at the duplicate $M D H-3,4^{*}$ and $G P I-1,2^{*}$ loci was arbitrarily assigned to $M D H-3^{*}$ and $G P I-1^{*}$, respectively. Vari- ation at the duplicate $I D D H-1,2 *$ was possible to assign to one locus or the other because of slight differences in mobility between the two loci; the more anodally migrating locus was $I D D H-2 *$. Allele frequencies were estimated by direct allele counts. A total of 39 additional loci were monomorphic in all populations. A fuller account of the genetic analyses will be presented elsewhere (Hindar et al., in preparation).

\section{Results}

\section{Asymmetry}

All meristic $\mathrm{R}-\mathrm{L}$ values exhibited asymmetry, with means not significantly different from zero (i.e. no directional symmetry is present). Twenty-four of the total of $30 \mathrm{R}-\mathrm{L}$ distributions were leptokurtic, whereas the rest were slightly but not significantly platykurtic $(P>0.05)$. Thus no antisymmetry is present and all $\mathrm{R}-\mathrm{L}$ distributions show fluctuating asymmetry.

The level of asymmetry for the different meristic characters (measured as the absolute value of the $\mathrm{R}-\mathrm{L}$ value of each character) varied both within populations (among origin groups; wild vs. hatchery) and among populations (Table 1). The absolute asymmetry values are not normally distributed, and we tested for differences using the Wilcoxon one-way analysis of variance by ranks using the Bonferroni adjustment of significance levels. The asymmetry values for any of the meristic characters for the Imsa fish of wild or hatchery origin did not differ $(P>0.05)$. The wild Lone juveniles had significantly lower pectoral fin asymmetry values than the hatchery juveniles $(Z=2.65, \quad N=77, \quad P<0.05)$, whereas there were no differences for the other meristic characters $(P \gg 0.05)$. The wild Ogna juveniles had significantly lower absolute asymmetry values than the hatchery Ogna fish for the lower gill rakers $(Z=3.32, N=43, P<0.05)$, whereas there were no such differences for the other meristic characters $(P \gg 0.05)$.

There were significant differences in mean number of asymmetric characters per individual among groups (Table 1; Krustal-Wallis test; $\left.\chi_{5}^{2}=44.8, P<0.001\right)$. We used the post-hoc TukeyKramer Honestly Significant Difference test $(\alpha=0.05)$ to evaluate which group means were significantly different. The Ogna hatchery population had a significantly higher mean number of asymmetric characters than all other populations, whereas the Ogna wild population had a significantly lower mean 
Table 1 Variation in fluctuating asymmetry for each meristic character in wild and hatchery Atlantic salmon from Imsa, Lone and Ogna

\begin{tabular}{lcccccc}
\hline Characters & Imsa wild & Imsa hatchery & Ogna wild & Ogna hatchery & Lone wild & Lone hatchery \\
\hline Pectoral fins & $0.27(0.55)$ & $0.36(0.48)$ & $0.20(0.50)$ & $0.22(0.46)$ & $0.08(0.28)$ & $0.38(0.61)$ \\
Pelvic fins & $0.06(0.24)$ & $0.12(0.33)$ & $0.04(0.20)$ & $0.02(0.15)$ & $0.02(0.14)$ & 0 \\
Upper gill rakers & $0.55(0.61)$ & $0.40(0.61)$ & $0.25(0.44)$ & $0.33(0.55)$ & $0.39(0.49)$ & $0.29(0.52)$ \\
Lower gill rakers & $0.48(0.58)$ & $0.76(0.92)$ & $0.08(0.41)$ & $0.61(0.70)$ & $0.48(0.55)$ & $0.48(0.50)$ \\
Mandibular pores & $0.42(0.65)$ & $0.28(0.45)$ & $0.08(0.28)$ & $0.33(0.52)$ & $0.37(0.49)$ & $0.36(0.49)$ \\
No. asymmetric characters & $1.64(0.92)$ & $1.66(1.17)$ & $0.58(0.58)$ & $2.18(1.05)$ & $1.32(0.99)$ & $1.41(0.92)$ \\
\hline
\end{tabular}

Asymmetry is measured as the absolute value of the right minus left value of pectoral and pelvic fins, upper and lower gillrakers and mandibular pores $( \pm S D)$.

Mean number of asymmetric characters per individual and locality is also given.

Table 2 Expected and observed heterozygosities of Atlantic salmon (Salmo salar) from three wild and three hatchery populations in south-western Norway

\begin{tabular}{|c|c|c|c|c|c|c|c|c|c|c|c|c|}
\hline \multirow[b]{2}{*}{ Locus } & \multicolumn{2}{|c|}{ Imsa wild } & \multicolumn{2}{|c|}{ Imsa hatchery } & \multicolumn{2}{|c|}{ Ogna wild } & \multicolumn{2}{|c|}{ Ogna hatchery } & \multicolumn{2}{|c|}{ Lone wild } & \multicolumn{2}{|c|}{ Lone hatchery } \\
\hline & $H_{\text {exp }}$ & $H_{\mathrm{obs}}$ & $H_{\text {exp }}$ & $H_{\text {obs }}$ & $H_{\text {exp }}$ & $H_{\text {obs }}$ & $H_{\text {exp }}$ & $H_{\mathrm{obs}}$ & $H_{\text {exp }}$ & $H_{\mathrm{obs}}$ & $H_{\text {exp }}$ & $H_{\mathrm{obs}}$ \\
\hline$A A T-4^{*}$ & 0.11 & 0.12 & 0.17 & 0.19 & 0.32 & 0.40 & 0.12 & 0.13 & 0.09 & 0.07 & No data & \\
\hline$F B A L D-3^{*}$ & 0.06 & 0.06 & 0.10 & 0.10 & 0 & 0 & 0.06 & 0.06 & 0.23 & 0.26 & No data & \\
\hline$\beta G L U A^{*}$ & 0 & 0 & 0 & 0 & 0 & 0 & 0 & 0 & 0.02 & 0.02 & 0 & 0 \\
\hline$G P I-1,2^{*}$ & 0.02 & 0.02 & 0 & 0 & 0 & 0 & 0 & 0 & 0 & 0 & 0 & 0 \\
\hline$I D D H-1^{*}$ & 0.04 & 0.04 & 0.11 & 0.12 & 0.05 & 0.05 & 0 & 0 & 0.04 & 0.04 & 0 & 0 \\
\hline$I D D H-2^{*}$ & 0.50 & 0.41 & 0.50 & 0.50 & 0.49 & 0.25 & 0.50 & $0.82^{* * *}$ & 0.41 & 0.46 & 0.49 & 0.62 \\
\hline$L D H-4^{*}$ & 0 & 0 & 0 & 0 & 0.08 & 0.08 & 0 & 0 & 0 & 0 & 0 & 0 \\
\hline$M D H-3,4^{*}$ & 0.01 & 0.01 & 0 & 0 & 0 & 0 & 0 & 0 & 0.04 & 0.04 & 0.29 & 0.35 \\
\hline$M E P-2 *$ & 0.39 & 0.33 & 0.49 & 0.49 & 0.49 & $0.33^{*}$ & 0.50 & $0.76^{* * *}$ & 0.47 & 0.54 & 0.50 & 0.50 \\
\hline$T P I-1^{*}$ & 0.08 & 0.08 & 0.08 & 0.08 & 0 & 0 & 0.37 & $0.49 *$ & 0 & 0 & 0 & 0 \\
\hline$T P I-3^{*}$ & 0.27 & 0.28 & 0.04 & 0.04 & 0.30 & 0.38 & 0.49 & $0.71^{* *}$ & 0.39 & 0.35 & 0.48 & 0.41 \\
\hline Average & 0.134 & 0.124 & 0.136 & 0.138 & 0.157 & 0.136 & 0.184 & 0.269 & 0.154 & $\hat{u} 163$ & $0.195 \dagger$ & $0.209 \dagger$ \\
\hline
\end{tabular}

Asterisks in the first column are part of the locus designation.

${ }^{*} P<0.05,{ }^{* *} P<0.01,{ }^{* * *} P<0.001$ in tests of deviation from Hardy-Weinberg proportions.

$\dagger$ Average based on nine loci (excluding $A A T-4^{*}$ and $F B A L D-3^{*}$ ).

number of asymmetric characters than all other populations except the Lone hatchery population.

\section{Heterozygosity and asymmetry}

Average heterozygosities at the eleven variable loci ranged between 0.134 and 0.184 based on expected values (which assume Hardy-Weinberg proportions), and between 0.124 and 0.269 based on observed values (Table 2). In both cases, the extreme values were found in the Imsa wild (low heterozygosity) and Ogna hatchery (high heterozygosity) populations (the figures for the Lone hatchery populations, $H_{\exp }=0.195$ and $H_{\mathrm{obs}}=0.209$, refer to nine loci, and are lower than the corresponding figures for the Ogna hatchery population).
This apparent difference in average heterozygosity between groups is not significant (ANOVA on arcsinesquare root transformed expected heterozygosities, $\left.F_{5,292}=0.025, P>0.9\right)$.

Within populations, there was no correlation between the number of heterozygous loci and number of asymmetric characters per individual for the five meristic characters (Spearman's rank correlation; all correlations gave $P \gg 0.05$; Table 3). Four out of six correlations were positive (not significant), whereas the hypothesis tested was that the correlations should be negative. The Imsa wild and the Ogna hatchery populations showed negative correlations between FA and heterozygosity as expected, but with very low correlation coefficients. We tested for power and estimated the least significant number 
Table 3 Number of heterozygous loci and number of asymmetric characters in wild and hatchery salmon from the rivers Imsa, Lone and Ogna

\begin{tabular}{|c|c|c|c|c|c|c|c|}
\hline \multirow[b]{2}{*}{ Location } & \multirow[b]{2}{*}{ Asymm. char. } & \multicolumn{5}{|c|}{$\begin{array}{l}\text { Number of heterozygous } \\
\text { loci }\end{array}$} & \\
\hline & & 1 & 2 & 3 & 4 & 5 & \\
\hline \multirow[t]{4}{*}{ Imsa wild } & 0 & 0 & 7 & 3 & 2 & 0 & \\
\hline & 1 & 4 & 12 & 12 & 3 & 1 & \\
\hline & 2 & 3 & 13 & 12 & 9 & 2 & $r=-0.026$ \\
\hline & 3 & 2 & 6 & 7 & 4 & 0 & $P=0.79$ \\
\hline \multirow[t]{6}{*}{ Imsa hatchery } & 0 & 2 & 1 & 5 & 0 & 0 & \\
\hline & 1 & 3 & 3 & 4 & 6 & 0 & \\
\hline & 2 & 1 & 4 & 2 & 6 & 2 & \\
\hline & 3 & 0 & 4 & 3 & 1 & 0 & \\
\hline & 4 & 0 & 0 & 2 & 0 & 0 & $r=0.125$ \\
\hline & 5 & 0 & 0 & 1 & 0 & 0 & $P=0.39$ \\
\hline \multirow[t]{3}{*}{ Ogna wild } & 0 & 3 & 4 & 3 & 1 & 0 & \\
\hline & 1 & 2 & 6 & 4 & 1 & 0 & $r=0.007$ \\
\hline & 2 & 1 & 1 & 0 & 0 & 0 & $P=0.97$ \\
\hline \multirow[t]{5}{*}{ Ogna hatchery } & 0 & 0 & 0 & 1 & 1 & 0 & \\
\hline & 1 & 1 & 1 & 2 & 7 & 0 & \\
\hline & 2 & 0 & 3 & 8 & 7 & 3 & \\
\hline & 3 & 0 & 1 & 5 & 4 & 0 & $r=-0.100$ \\
\hline & 4 & 0 & 1 & 2 & 4 & 0 & $P=0.48$ \\
\hline \multirow[t]{5}{*}{ Lone wild } & 0 & 0 & 0 & 0 & 0 & 0 & \\
\hline & 1 & 0 & 2 & 8 & 2 & 0 & \\
\hline & 2 & 3 & 5 & 5 & 1 & 0 & \\
\hline & 3 & 4 & 7 & 4 & 2 & 0 & $r=-0.089$ \\
\hline & 4 & 0 & 1 & 1 & 1 & 0 & $P=0.47$ \\
\hline \multirow[t]{5}{*}{ Lone hatchery } & 0 & 0 & 0 & 0 & 0 & 0 & \\
\hline & 1 & 0 & 2 & 6 & 0 & 0 & \\
\hline & 2 & 0 & 1 & 7 & 5 & 0 & \\
\hline & 3 & 0 & 1 & 4 & 4 & 0 & $r=0.284$ \\
\hline & 4 & 0 & 0 & 1 & 0 & 0 & $P=0.12$ \\
\hline
\end{tabular}

The Spearman rank correlations $(r)$ with associated $P$-values are given.

(LSN) of observations necessary to get $P=0.05$. For the Imsa wild population power was 0.058 and LSD $>5000$, for the Ogna hatchery population power was 0.107 and LSN was 391 . We can therefore confidently reject the hypothesis that there is a significant negative correlation between FA and heterozygosity in our samples. Among populations, average expected heterozygosity showed no significant association with the mean number of asymmetric characters (Spearman's $r=0.03, N=6$, $P>0.05)$.

\section{Environmental stress and asymmetry}

We did not find any association between individual growth rate and asymmetry level within any of the six groups of Atlantic salmon juveniles (correlation analysis; $P \gg 0.05$ in all tests). Between groups, the faster growth rate experienced in the hatchery was not reflected in less asymmetric fish. On the contrary, the only significant change (Ogna wild vs. Ogna hatchery) was in the opposite direction of that expected from considerations of individual growth rate alone.

Survival rate in the hatchery was highest in the Imsa fish and lowest in the Ogna. Between 20 February and 8 October 1990, when most of the mortality occurred, the cumulative survival of the three groups was (mean $\pm \mathrm{SE}$ (per cent)): Imsa $73.6 \pm 0.2$; Lone 63.2 \pm 0.2 ; Ogna $43.4 \pm 0.8$. These survival patterns are significantly different $\left(\chi_{2}^{2}=3464.8, P<0.001\right)$. 


\section{Discussion}

Heterozygosity, as estimated by enzyme electrophoresis, is not correlated with developmental stability within the six groups of Atlantic salmon studied here. This is remarkable in light of the previous studies of salmonids, which have indicated that the fluctuating asymmetry of meristic characters increases with decreasing heterozygosity (Leary et al., 1983, 1984, 1985, 1992; Blanco et al., 1990). Upon closer inspection, however, this relationship is not very strong. Leary et al. (1992) present data from 20 populations of rainbow trout, and in only four of these populations did they find significant negative correlations between heterozygosity and FA. Further, most studies on fish and other animals indicate that the correlation between heterozygosity and FA if present, is very weak (only about 5 per cent of the variation in FA can be explained by the measured variation in heterozygosity) (Gillespie, 1991; Leary et al., 1992; Clarke, 1993; Mitton, 1993).

Most of the few significant correlations found within salmonid populations result from observations in hatchery populations. Leary et al. (1992) showed significant correlations between heterozygosity and FA in four out of 17 hatchery populations and in none of the three natural populations studied. Moreover, Blanco et al. (1990) found a negative correlation in two out of two hatchery populations and in one out of two natural populations. The published evidence for a negative relationship between heterozygosity and FA within salmonid populations is therefore almost exclusively related to hatchery-reared populations.

Our results show that the hatchery environment may have a strong influence on levels of FA. The Ogna salmon raised in the hatchery had a significantly higher level of FA than the salmon which had lived their entire life in the Ogna. In contrast, wild and hatchery fish of Imsa and Lone origin had the same level of FA. We suggest that this marked difference between one population which was novel to the hatchery environment, and two populations which had been sea-ranched there for 10 years, is caused by maladaptation of River Ogna fish to the hatchery.

The higher mortality of the Ogna hatchery fish compared with the Imsa and Lone hatchery fish supports the idea that the former are maladapted when raised in the hatchery at Ims. Lack of adaptation to the captive environment, rather than lack of adaptation to Imsa water, seems to be the cause for higher mortality. The Imsa and Lone populations have been sea-ranched in the Imsa for 10 years (approx. three generations). This time period seems sufficient for at least adaptation to the captive environment. Fleming \& Gross (1992) documented clear differences in the reproductive potential of hatchery relative to wild coho salmon Oncorhynchus kisutch during competition after four generations of sea-ranching, and concluded that the difference was caused by genetic adaptation to the captive environment. Similarly, intense natural selection in populations brought into captivity has been suggested as a cause for rapid loss of genetic variation in experimental Drosophila populations (Briscoe et al., 1992). In concordance with this explanation, two other salmon populations, which were taken into the Ims hatchery at the same time as the Ogna fish, showed significantly lower survival during the first year of life than the Imsa fish (unpublished results). At present, however, we do not know whether they were also more asymmetric.

Water quality differences cannot explain the variation in FA between populations. The three rivers studied here are similar in physical and chemical characteristics, and we find it unlikely that water quality differences may induce significantly increased asymmetry when Ogna fish are raised in Imsa water. If anything, Imsa water quality is more benign than Ogna and Lone water. Rearing density, another environmental factor with a suggested effect on asymmetry (Leary et al., 1991), cannot provide an explanation for increased asymmetry in Ogna hatchery fish because they experienced a lower rearing density than the Imsa and Lone hatchery fish, and thus should be less asymmetric from the latter from this cause alone. Again, the opposite was observed.

Significant deviation of the Ogna hatchery fish from Hardy-Weinberg equilibrium at four out of six variable loci indicates that our hatchery sample may not be a good representation of river Ogna fish. All deviations resulted from an excess of heterozygotes, which can be explained by either (1) genetic differences between the sexes of the broodstock used, or (2) heterozygote advantage of the offspring in the hatchery. Genetic differences between the sexes can only explain excesses of heterozygotes of the magnitudes reported here if the allele frequency differences between the sexes were 0.5 or larger at each of the four loci (Hedrick, 1983, pp. 48-50). One way this could be related to increased FA is if males and females were sampled from genetically divergent populations. In that case, our observation would support the notion that lack of genomic coadaptation may be a cause of high FA (Clarke, 1993).

We find it unlikely, however, that two divergent 
populations were crossed to form the Ogna hatchery population. Allele frequency differences of 0.5 or more between Atlantic salmon populations are not known from Norway (Ståhl \& Hindar, 1988; Hindar, unpublished), except at the $M E P-2 *$ locus where there is extensive clinal variation and where the common $\left(100^{*}\right)$ allele seems to be favoured in farmed fish. Escaped farmed salmon have been observed among spawners sampled in the River Ogna (Moen \& Gausen, 1989), but it is unlikely that they were picked as broodstock, because their phenotype differs from wild fish (Fleming et al., 1994), and because no farmed contribution is apparent from a comparison of $M E P-2 *$ allele frequencies in wild and hatchery Ogna fish (Fisher's exact test; $P=0.72$ ). A more likely explanation is that only a few river Ogna fish contributed effectively to the hatchery population, and that this number was considerably smaller than the 7-12 individuals of each sex which were picked as broodstock.

Heterozygote advantage in the hatchery is another explanation for the observed excess of heterozygotes in Ogna hatchery fish. Most inheritance studies of allozymes in Atlantic salmon however, have, not found signs of differential viability of the various genotypes (Crozier \& Moffett, 1990).

We conclude that the hypothesized correlation between level of heterozygosity and FA is not met in this comparative analysis. Increased asymmetry of only one of the transplanted populations seems to be caused by maladaptation to the captive environment, rather than by varying levels of heterozygosity, water quality, temperature or density.

\section{Acknowledgements}

We thank Nina Jonsson, Harald Sægrov and Gunnel $\emptyset$ stborg for collecting and aging fish, Jon Backer and the staff at the Research Station for Freshwater Fish at Ims for raising the fish, Torveig Balstad for laboratory analyses, and Moira Ferguson, Ian Fleming and Nils Ryman for comments on the manuscript. The Research Council of Norway and the Directorate for Nature Management provided financial support.

\section{References}

AEBERSOLD, P. B., WINANS, G. A., TEEL, D. J., MILNER, G. B. AND UTTER, F. M. 1987. Manual for Starch Gel Electrophoresis: A Method for the Detection of Genetic Variation. NOAA Technical Report NMFS 61. U. S. Department of Commerce, National Oceanic and Atmospheric Administration, National Marine Fisheries
Service, Seattle, WA.

BEACHAM, T. D. 1991. Developmental stability, heterozygosity, and genetic analysis of morphological variation in pink salmon (Oncorhynchus gorbuscha). Can. J. Zool., 69, 274-278.

Blanco, G., Sánchez, J. A., VASQues, E., garcía, E. AND RUBIO, J. 1990. Superior developmental stability of heterozygotes at enzyme loci in Salmo salar L. Aquaculture, 84, 199-209.

BRISCOE, D. A., MALPICA, J. M., ROBERTSON, A., SMITH, G. J., FRANKHAM, R., BANKS, R. G. AND BARKER, J. S. F. 1992. Rapid loss of genetic variation in large captive populations of Drosophila flies: implications for the genetic management of captive populations. Conserv. Biol., 6, 416-425.

ClARKE, G. M. 1992. Fluctuating asymmetry: a technique for measuring developmental stress of genetic and environmental origin. Acta Zool. Fenn., 191, 31-35.

CLARKE, G. M. 1993. The genetic basis of developmental stability. I. Relationships between stability, heterozygosity and genomic coadaptation. Genetica, 89, 15-23.

CLARKE, G. M. 1995. Relationships between developmental stability and fitness: application for conservation biology. Conserv. Biol., 9, 18-24.

ClARKE, G. M., OLDROYD, B. P. AND HUNT, P. 1992. The genetic basis of developmental stability in Apis mellifera: heterozygosity versus genic balance. Evolution, 46, $753-762$.

CROZIER, w. W. AND MOFFETT, 1. J. J. 1990. Inheritance of allozymes in Atlantic salmon (Salmo salar L.). Aquaculture, 88, 253-262.

FERGUSON, M. M. AND IHSSEN, P. E. 1991. Distribution and phenotypic correlates of variation at enzyme coding loci in rainbow trout (Oncorhynchus mykiss) from the lower Laurentian Greak Lakes. Can. J. Fish. Aquat. Sci., 48, $1308-1315$.

FLEMING, I. A. AND GROSS, M. R. 1992. Reproductive behavior of hatchery and wild coho salmon (Oncorhynchus kisutch): does it differ? Aquaculture, 103, 101-121.

FLEMING, I. A., JoNSSON, B. AND GROSS, M. R. 1994. Phenotypic divergence of sea-ranched, farmed and wild salmon. Can. J. Fish. Aquat. Sci., 51, 2808-2824.

gillespie, J. H. 1991. The Causes of Molecular Evolution. Oxford University Press, New York.

HEDRICK, P. w. 1983. Genetics of Populations. Science Books International, Boston.

JAGOE, C. H. AND hAINES, T. A. 1985. Fluctuating asymmetry in fishes inhabitating acidified and unacidified lakes. Can. J. Zool., 63, 130-138.

JONSSON, B. 1976. Comparison of scales and otoliths for age determination in brown trout, Salmo trutta L. Nonw. J. Zool., 24, 295-301.

JORDAN, W. C., YOUNGSON, A. F., HAY, D. W. AND FERGU. SON, A. 1992. Genetic protein variation in natural populations of Atlantic salmon (Salmo salar) in Scotland temporal and spatial variation. Can. J. Fish. Aquat. Sci., 49, 1863-1872.

KARAKOUSIS, Y. AND TRIANTAPHYLLIDIS, C. 1992. Heterozygosity and morphological variability in brown trout 
(Salmo trutta L.) populations from Greece. Zool. Anzeiger., 228, 149-155.

LEARY, R. F. AND ALLENDORF, F. W. 1989. Fluctuating asymmetry as an indicator of stress: implications for conservation biology. Trends Ecol. Evol. 4, 214-217.

LEARY, R. F., ALLENDORF, F. W. AND KNUDSEN, K. L. 1983. Developmental stability and enzyme heterozygosity in rainbow trout. Nature, 301, 71-72.

LEARY, R. F., ALLENDORF, F. W. AND KNUDSEN, K. L. 1984. Superior developmental stability of heterozygotes at enzyme loci in salmonid fishes. Am. Nat., 124, 540-551.

LEARY, R. F., ALLENDORF, F. W. AND KNUDSEN, K. J. 1985. Developmental instability as an indicator of reduced genetic variation in hatchery trout. Trans. Am. Fish. Soc., 114, 230-235.

LEARY, R. F., ALLENDORF, F. W. AND KNUDSEN, K. L. 1991. Effects of rearing density on meristics and developmental stability in rainbow trout. Copeia, 1991, 44-49.

LEARY, R. F., ALLENDORF, F. W. AND KNUDSEN, K. L. 1992. Genetic, environmental, and developmental causes of meristic variation in rainbow trout. Acta Zool. Fenn., 191, 79-95.

MARKOW, T. A. 1995. Evolutionary ecology and developmental instability. Ann. Rev. Ent., 40, 105-120.

MITTON, J. B. 1993. Enzyme heterozygosity, metabolism, and developmental stability. Genetica, 89, 47-65.

MOEN, V. AND GAUSEN, D. 1989. Rømt oppdrettsfisk $i$ vassdrag 1988. Report 3-1989, Directorate for Nature
Management, Trondheim, Norway (in Norwegian).

PALMER, A. R. AND STROBECK, C. 1992. Fluctuating asymmetry as a measure of development stability: implications of non-normal distributions and power of statistical tests. Acta Zool. Fenn., 191, 57-72.

SHAKLEE, J. B., ALLENDORG, F. W., MORIZOT, D. C. AND whitT, G. s. 1990 . Gene nomenclature for proteincoding loci in fish. Trans. Am. Fish. Soc., 119, 2-15.

STEARNS, s. C. 1992. The Evolution of Life Histories. Oxford University Press, Oxford.

STÅHL, G. 1987. Genetic population structure of Atlantic salmon. In: Ryman, N. and Utter, F. (eds) Population Genetics and Fishery Management, pp. 121-140. University of Washington Press, Seattle.

STÅHL, G. AND HINDAR, K. 1988. Genetisk struktur hos norsk laks: status og perspektiver. Report No. 1-88, Directorate for Nature Management, Trondheim, Norway (in Norwegian).

VAN VALEN, L. 1962. A study of fluctuating asymmetry. Evolution, 16, 125-142.

VøLLESTAD, L. A., JONSSON, B., HVIDSTEN, N.-A. AND NÆSJE, T. F. 1994. Experimental test of environmental factors influencing the seaward migration of European silver eels. J. Fish Biol., 45, 641-651.

WILSON, I. F., BOURKE, E. A. AND CROSS, T. F. 1995. A triose-phosphate isomerase polymorphism in the Atlantic salmon Salmo salar L. Biochem. Genet., 33, 25-33. 